\title{
Organização estrutural da folha de Pimenta pseudocaryophyllus (Gomes) L.R. Landrum, Myrtaceae
}

\author{
Vanessa de Farias ${ }^{1,2}$, Ledyane Dalgallo Rocha ${ }^{1}$, Karla Heloise Preussler ${ }^{1}$ e Leila Teresinha Maranho ${ }^{1}$
}

Recebido em 2/10/2007. Aceito em 20/08/2008

\begin{abstract}
RESUMO - (Organização estrutural da folha de Pimenta pseudocaryophyllus (Gomes) L.R. Landrum, Myrtaceae). Com grande distribuição no Brasil e ocorrência principalmente no cerrado, caatinga e floresta atlântica, Pimenta pseudocaryophyllus (Gomes) L.R. Landrum, que está inclusa em um dos menores gêneros de Myrtaceae, é popularmente conhecida como craveiro-do-mato, louro-cravo ou chá-de-bugre. Trata-se de uma espécie nativa e suas folhas são usadas na culinária substituindo o cravo-da-índia (Syzygium aromaticum) devido ao aroma semelhante. O estudo tem o objetivo de caracterizar anatomicamente a folha dessa espécie. Para a confecção do laminário, amostras da região mediana da folha e do pecíolo foram seccionadas em micrótomo de rotação e coradas com azul de toluidina a $1 \%$. Em vista frontal, a epiderme é glabra na face adaxial e pilosa na face abaxial, com tricomas unicelulares. A folha é hipoestomática e os complexos estomáticos são anomocíticos. Em secção transversal, a epiderme é uniestratificada revestida por cutícula espessa e camada subepidérmica formada por 1-2 estratos celulares. O mesofilo é dorsiventral e bainha esclerenquimática envolve o feixe vascular bicolateral. Na folha e no pecíolo observam-se colênquima lacunar, flanges cuticulares, canais secretores e idioblastos contendo drusas e monocristais. Concluise que a espécie possui características freqüentes para Myrtaceae, com exceção da camada subepidérmica e flanges cuticulares, e que os resultados obtidos contribuem com novas informações que podem subsidiar estudos futuros no que se refere à identificação e delimitação do táxon.
\end{abstract}

Palavras-chave: anatomia foliar, drusas, estruturas secretoras, Myrtaceae, Pimenta

\begin{abstract}
Leaf structural organization of Pimenta pseudocaryophyllus (Gomes) L.R. Landrum, Myrtaceae). Pimenta pseudocaryophyllus (Gomes) L.R. Landrum is a native species from Brazil and occurs mainly in cerrado, caatinga and Atlantic rainforest vegetation. It is commonly known as "craveiro-do-mato", "louro-cravo" or "chá-de-bugre". It is a tree species whose leaves are used for cooking; they smell and taste like cloves (Syzygium aromaticum). This study describes the leaf anatomy of the species. The leaves were sliced with a microtome, stained with $1 \%$ toluidine blue and prepared on slides. The histological sections were from the medium section, between the edge and the midrib of the leaves The lower leaf epidermis has anomocytic stomata complexes and non-glandular coats. The epidermis is unicellular; its cells are covered by a thick cuticle. The mesophyll is dorsiventral. The bicollateral vascular bundles are sheathed. Idioblasts with druses, monocrystals and lisigenous secretory canals were found along the entire leaf blade. We conclude that leaf anatomy provides new information on the species, with structures common in leaves of Myrtaceae.
\end{abstract}

Key words: druses, leaf anatomy, Myrtaceae, Pimenta, secretory structures

\section{Introdução}

Myrtaceae Juss. possui cerca de 4.000 espécies, subordinadas a 130 gêneros, distribuídos pela América Tropical, Leste Asiático e Austrália (Barroso 1984; Souza \& Lorenzi 2005) e está dividida em duas subfamílias: Leptospermoideae e Myrtoideae. A primeira compreende Eucalyptus L'Hér., Leptospermum J.R. Forst. \& G. Forst. e Melaleuca L., que predominam na Austrália. A segunda, representada principalmente nas Américas do Sul e Central, apresenta os gêneros Eugenia L., Myrtus L., Pimenta Lindl., Pseudocaryophyllus O. Berg., Psidium L. e Syzygium P. Browne ex Gaertn. (Auricchio \& Bacchi 2003; Romagnolo \& Souza 2004).
No Brasil, estima-se que exista cerca de $30 \%$ dos representantes da família, o que explica o grande número de citações em diversos levantamentos florísticos e fitossociológicos (Landrum \& Kawasaki 1997; Pinto et al. 2005). Com distribuição no cerrado, caatinga, restinga, floresta atlântica e florestas deciduais, a família caracteriza-se como a mais importante ou uma das mais importantes famílias brasileiras (França \& Stehmann 2004; Meyer et al. 2004; Cardoso \& Sajo 2006; Pereira et al. 2006).

Fabris \& César (1996) atribuíram grande importância ecológica ao taxa, pois seus representantes prosperam em solos contendo baixa quantidade de magnésio e fósforo, com pouca drenagem e com baixa quantidade

\footnotetext{
Universidade Positivo, Rua Prof. Pedro Viriato Parigot de Souza 5300, Bairro Campo Comprido, 81280-330 Curitiba, PR, Brasil

2 Autora para correspondência: vanessaprass@yahoo.com.br
} 
de nutrientes. Além disso, possuem diversos usos, tais como medicinal, alimentício, aromático e industrial (Limberger et al. 1998; Donato \& Morretes 2007).

Souza \& Lorenzi (2005) citaram que, além da família ser uma das mais complexas do ponto de vista taxonômico, apresenta um grande número de espécies e uma escassez de estudos sobre as mesmas. Desse modo, diversos levantamentos fitossociológicos citam um elevado número de taxa indeterminados (Romagnolo \& Souza 2004). Para evitar informações imprecisas ou incompletas, Landrum \& Kawasaki (1997), destacaram a importância de coletar materiais com frutos e flores, para que dessa forma, possa ocorrer a identificação correta do grupo.

Pimenta possui cerca de 15 espécies distribuídas na América, estando sua maioria localizada no Caribe. No Brasil ocorre apenas Pimenta pseudocaryophyllus (Gomes) L.R. Landrum com três variedades: var. pseudocaryophyllus, var. fulvescens (DC.) Landrum e var. hoehnei (Burret) Landrum (Landrum \& Kawasaki 1997).

Pimenta pseudocaryophyllus é popularmente conhecida como pau-cravo, craveiro-do-mato, lourocravo ou chá-de-bugre. É uma árvore aromática recomendada para a urbanização e para reflorestamentos, com distribuição na Bahia, Minas Gerais, Goiás até Santa Catarina. É uma planta nativa, semidecídua, seletiva xerófita e pioneira, sendo exclusiva de florestas de altitude e da caatinga (Legrand \& Klein 1978; Lorenzi 2002).

Em estudo que avaliou o potencial antifúngico de óleos essenciais de diversas espécies, Maciel (comunicação pessoal) revelou que o óleo proveniente das folhas de P. pseudocaryophyllus demonstra atividade antifúngica semelhante ao cravo-da-índia (Syzygium aromaticum (L.) Merr. \& L.M. Perry.). Folhas de P. pseudocaryophyllus podem ser utilizadas na forma de infusão para estados gripais (Limberger et al. 1998; Paula et al. 2005) ou serem utilizadas como condimento substitutivo do cravo-da-índia, em doces e geléias, pois as duas espécies possuem cheiro aromático e sabor ardente característico e semelhante. Desde o século XIX, há correlação entre essas espécies, as quais são exploradas medicinalmente e utilizadas em diversos tratamentos (Corrêa \& Gottlieb 1970; Dorman \& Deans 2000; Mazzafera 2003; Sanjad 2004; Viuda-Martos et al. 2007).

Girard (dados não publicados) citou que o óleo essencial proveniente de $P$. pseudocaryophyllus possui várias aplicações, como em aromatizantes, cosméticos, perfumes e inseticidas e na indústria fármaco-medicinal, dada às suas propriedades analgésicas, antibacterianas e sedativas. Craveiro et al. (1981) e Lehtonen (1982) caracterizam o eugenol como o principal constituinte do óleo essencial de P. pseudocaryophyllus que, segundo Newall et al. (2002), é o principal componente ao qual pode-se atribuir as propriedades anti-sépticas que algumas plantas apresentam.

Estudos anatômicos referentes ao táxon são escassos, principalmente, levando-se em conta a grande representatividade das Myrtaceae no Brasil. Os trabalhos relacionados ao gênero Pimenta são, predominantemente, de cunho fitoquímico e farmacológico, como em Pimenta dioica (L.) Merr., P. acris (Sw.) Kostel. e P. racemosa (Mill.) J.W. Moore (Palkin \& Wells 1933; Gottlieb et al. 1970; Garcia et al. 2002; Starr et al. 2003; Miyajima et al. 2004).

Conforme relatado por Cardoso \& Sajo (2004), os demais representantes de Myrtaceae são, igualmente, pouco estudados anatomicamente destacando-se, entretanto, o estudo pioneiro de Johnson (1980), sobre a anatomia de Leptospermum, o de Gomes \& Neves (1997), que descreve a anatomia foliar de Gomidesia spectabilis (DC.) O. Berg e G. nitida (Vell.) Nied., e alguns referentes ao gênero Eugenia (Van Wyk et al. 1982; Machado et al. 1988; Fontenelle et al. 1994; Auricchio \& Bacchi 2003; Cardoso \& Sajo 2004). O estudo mais recente referente à anatomia foliar de Myrtaceae é o de Donato \& Morretes (2005), que descreve a anatomia foliar de Psidium widgrenianum $\mathrm{O}$. Berg. O presente estudo tem como objetivo caracterizar anatomicamente a folha de P. pseudocaryophyllus.

\section{Material e métodos}

O material examinado foi coletado em um fragmento de Floresta Ombrófila Mista (Floresta com Araucária) em Curitiba, PR, entre as coordenadas geográficas $25^{\circ} 35^{\prime} 01,2^{\prime \prime}$ 'S e $49^{\circ} 15^{\prime} 43,7^{\prime \prime}$ W. Foram selecionados três indivíduos de Pimenta pseudocaryophyllus (Gomes) L.R. Landrum, dos quais foram coletadas 15 folhas por indivíduo, estando estas totalmente expandidas e posicionadas a partir do $4^{\circ}$ nó caulinar. O material foi imediatamente fixado com FAA 70 por 48 horas (Johansen 1940) e, posteriormente, conservado em etanol a $70 \%$ até o processamento final (Berlyn \& Miksche 1976). Para a confecção do laminário foram preparadas lâminas permanentes e semi-permantes.

Para obtenção das lâminas permanentes foram selecionadas amostras da região mediana da lâmina foliar, do pecíolo e bordo, estas foram incluídas em metacrilatoaglicol (JB-4) adotando-se o procedimento descrito por Feder \& O'brien (1968) e recomendações do fabricante (POLYSCIENCES INC). As secções foram feitas em micrótomo de rotação (LEICA RM2125) com espessura de $7 \mu \mathrm{m}$ e coradas, posteriormente, com azul de toluidina a 1\% (Sakai 1973). As lâminas foram montadas com resina sintética $\left(\right.$ Entelan $\left.^{\circledR}\right)$.

Para o preparo das lâminas semi-permanentes foram realizadas secções transversais à mão livre da região 
mediana da folha. A diafanização foi efetuada mediante o emprego de hipoclorito de sódio a $20 \%$ e o $\mathrm{pH}$ foi neutralizado com água acidulada. As secções foram coradas com Safrablau (Kraus \& Arduim 1997). Testes histoquímicos foram feitos em secções realizadas à mão livre, de material fresco, submetidas ao Sudan III (Johansen 1940), para observação de compostos de natureza lipídica. Como meio de montagem utilizou-se glicerina e a lutagem foi feita com esmalte incolor. No preparo de lâminas para visualização da epiderme foram selecionadas amostras da região mediana, em que as epidermes foram separadas empregando-se o método proposto por Franklin (1946) e coradas com azul de toluidina a $0,05 \%$ (Sakai 1973). As lâminas foram montadas com glicerina e a lutagem foi feita com esmalte incolor.

A descrição das secções transversais e paradérmicas foi feita mediante o emprego do microscópio fotônico (OLYMPUS - CX41RF). O fotomicroscópio (OLYMPUS - BX 41), com captura de imagem, foi utilizado para obtenção das ilustrações, sendo as escalas obtidas nas mesmas condições das fotos.

\section{Resultados}

As folhas de $P$. pseudocaryophyllus são simples, inteiras, curtamente pecioladas, peninérveas e de consistência coriácea. Possuem coloração verde-escura na face superior e verde-prateada na face inferior, medindo entre 10 e $17 \mathrm{~cm}$ de comprimento por 3 e $5 \mathrm{~cm}$ de largura. A filotaxia é oposta-cruzada. As folhas são glabras na superfície adaxial e pilosas na superfície abaxial. A lâmina tem forma lanceolada com as margens levemente onduladas, o ápice é agudo e a base acunheada.

Em vista frontal, a epiderme em sua face adaxial exibe células com formatos irregulares, paredes anticlinais espessas, retas a levemente sinuosas, ausência de estômatos e tricomas (Fig. 1-2). As regiões da epiderme que recobrem as cavidades secretoras são identificadas por serem constituídas por apenas um par de células, com formato reniforme (Fig. 2) e por apresentarem uma sinuosidade característica em sua parede mediana. As demais células epidérmicas dispõem-se radialmente ao redor do par de células que cobrem o canal lisígeno (Fig. 2).

A face abaxial da epiderme exibe células de paredes anticlinais espessas e retas a levemente sinuosas (Fig. 3), além de grande quantidade de complexos estomáticos do tipo anomocítico, circundados por 3 a 6 células epidérmicas (Fig. 3-5). Além disso, inúmeros tricomas unicelulares tectores alongados podem ser encontrados, estando estes inclinados e dispostos na mesma direção (Fig. 6-7).
Ainda em vista frontal, na região da nervura principal, são observadas células alongadas dispostas paralelamente, as quais acompanham o curso da nervura principal e das nervuras secundárias. Os tricomas diminuem nesta região (Fig. 7) e os estômatos, quando presentes, apresentam maior tamanho quando comparados àqueles das regiões intercostais.

A epiderme, em secção transversal, é uniestratificada (Fig. 8-11) e o mesofilo é dorsiventral (Fig. 8-9). As células epidérmicas na face adaxial são maiores quando comparadas à face abaxial. Internamente à face adaxial, observa-se camada subepidérmica composta por 1-2 estratos de células (Fig. 9). Estas células possuem maior volume e são mais arredondadas quando comparadas com as que compõem a epiderme. Uma cutícula espessa está depositada sobre as paredes periclinais externas da epiderme adaxial, a qual se prolonga em direção às paredes anticlinais, formando flanges cuticulares. Uma cutícula com menor espessamento é observada sobre a face abaxial na epiderme e esta apresenta, ainda, estômatos ocupando posição ligeiramente superior às demais células epidérmicas.

No mesofilo, o parênquima paliçádico (Fig. 9) é constituído por 2-3 estratos de células retangulares e alongadas no eixo vertical, as quais se dispõem de forma organizada, por apresentarem as paredes anticlinais justapostas com as células adjacentes, formando fileiras abaixo da camada subepidérmica. O parênquima lacunoso é formado por 6-8 estratos. Diversos idioblastos, portadores de drusas (Fig. 12) e cristais prismáticos (Fig. 13), são observados no mesofilo, sendo grande a ocorrência dos primeiros. Feixes vasculares colaterais estão imersos no mesofilo e envolvidos por fibras esclerenquimáticas.

Canais lisígenos (Fig. 8-11) ocorrem em posição subepidérmica em ambas as faces da lâmina, porém, em maior número na face adaxial. Os canais secretores apresentam formato esférico, delimitado por células ligeiramente achatadas. Nota-se que o lúmen do canal comunica-se com o exterior através de dois a quatro pares de células, as quais se encontram imersas na camada subepidérmica e na epiderme, permitindo que o produto secretado possa ser liberado sem que ocorra o rompimento das células epidérmicas.

Na região da nervura central (Fig. 10), da periferia para o centro, nota-se uma cutícula espessa sobre a epiderme, sendo o espessamento maior sobre a face adaxial. Flanges cuticulares são observadas na face adaxial na epiderme, a qual constitui um prolongamento das paredes periclinais externas. A epiderme revela-se uniestratificada e pode-se observar ocasionalmente, em sua face abaxial, tricomas tectores unicelulares localizados na região de transição com o mesofilo. Nota- 
se ainda, na região subepidérmica de ambas as faces da epiderme, canais lisígenos e 3-4 estratos de colênquima lacunar (Fig. 10), estando este tecido presente em ambas às faces. A seguir, ocorrem células do parênquima que envolvem o feixe vascular central, essas células inicialmente são de pequeno diâmetro na região periférica, entretanto, aumentam gradativamente ao aproximar-se do feixe vascular, e posteriormente, reduzem novamente na região adjacente ao feixe vascular (Fig. 10).

O feixe vascular central possui a forma de um arco, o qual na face adaxial é sulcado e na face abaxial é côncavo (Fig. 10). O xilema revela células dispostas em fileiras radiais (Fig. 10). Este apresenta em seus pólos o
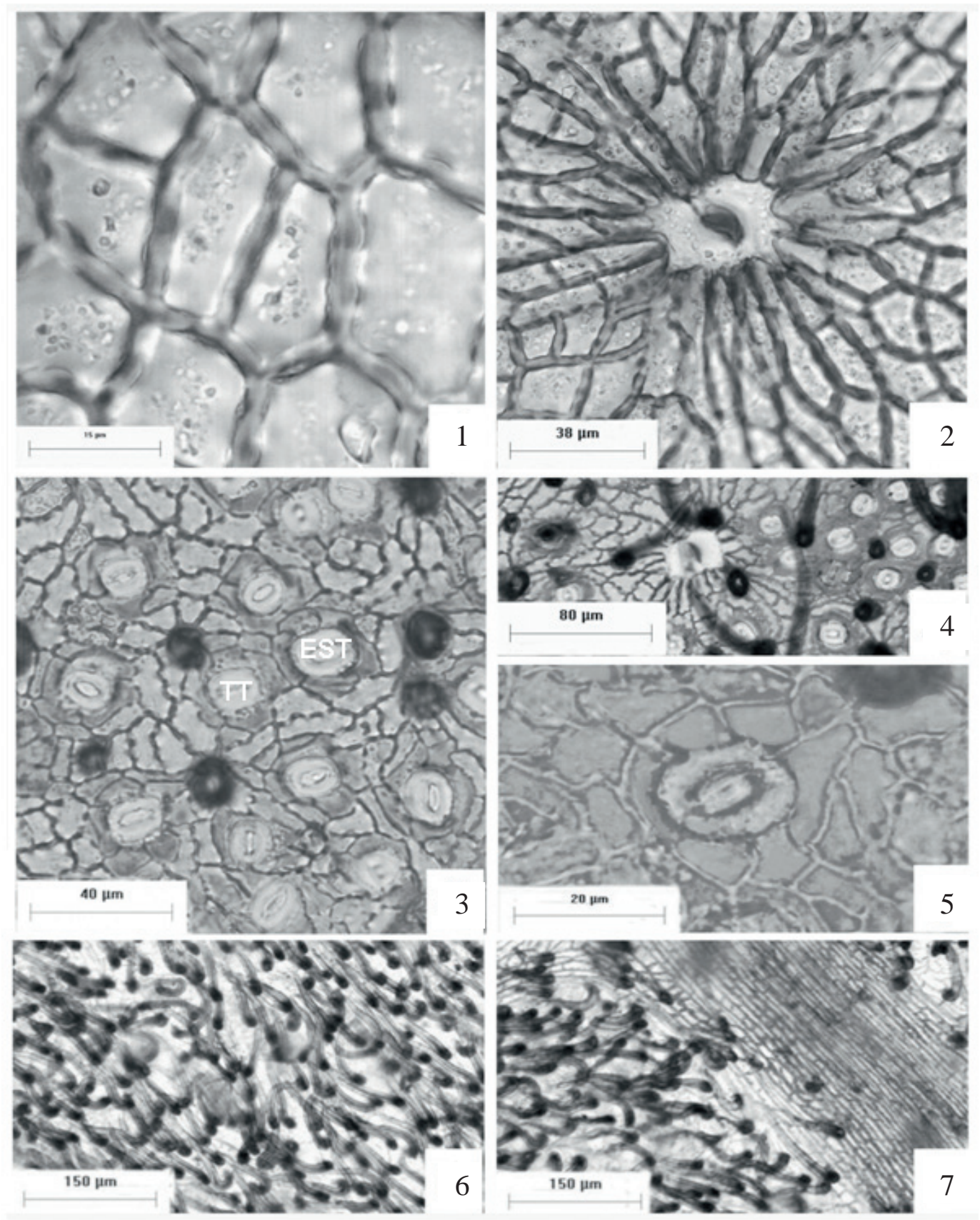

Figuras 1-7. Vista frontal da epiderme foliar de Pimenta pseudocaryophyllus (Gomes) L.R. Landrum. 1. Face adaxial. 2. Face adaxial, detalhe do par de células reniformes que cobrem o canal secretor. 3. Face abaxial, estômatos anomocíticos e células que cobrem o canal secretor. 4. Face abaxial, complexos estomáticos anomocíticos, tricomas tectores e par de células reniformes. 5. Face abaxial, detalhe de complexo estomático anomocítico circundado por seis células epidérmicas fundamentais. 6. Face abaxial, tricomas unicelulares tectores. 7. Face abaxial exibindo diminuição dos tricomas tectores na região nervural. (EST = estômato; TT = cicatriz tricoma tector). 
floema, constituído por um maior número de camadas voltadas para a face adaxial. Fibras esclerenquimáticas envolvem o feixe vascular que é fechado.

$\mathrm{O}$ bordo foliar apresenta-se levemente fletido para a face abaxial. A epiderme é uniestratificada, com paredes anticlinais espessas. Da região de nervura principal em direção ao bordo foliar, observa-se nas células epidérmicas uma redução no comprimento, porém, a mesma altura; a cutícula torna-se mais espessa, com formação de flanges cuticulares; e o mesofilo torna-se homogêneo, com parênquima clorofiliano formado por oito estratos. Tricomas unicelulares tectores, estômatos, drusas e canais secretores estão presentes até a região que limita o parênquima paliçádico.

O pecíolo (Fig 14), em secção transversal, possui superfície adaxial plana à ligeiramente côncava e a abaxial, convexa. A epiderme é uniestratificada, composta por células com formatos irregulares, podendo ser triangulares, quadradas ou esféricas com paredes espessas. Estômatos e tricomas estão ausentes. Uma cutícula espessa está depositada sobre as paredes periclinais externas da epiderme. Flanges cuticulares são observadas por toda a superfície do pecíolo, podendo ser observada principalmente na face abaxial, onde a cutícula é mais espessa. Em posição subepidérmica observa-se uma faixa de colênquima lacunar, formado por 5-10 estratos. A região correspondente ao parênquima fundamental é formada por 13-22 estratos, com células de paredes espessas e com vários idioblastos portadores de drusas. Canais secretores e drusas podem ser observados em toda a periferia do pecíolo, nos tecidos colenquimático e parenquimático.

O sistema vascular (Fig. 15) está disposto em forma de arco e encontra-se circundado por uma bainha esclerenquimática que varia de 4-7 estratos de células. O xilema é constituído de 20-22 estratos. O floema que está voltado para a face adaxial possui maior número de estratos, de 23-30, enquanto aquele voltado para a face abaxial possui de 13-15. Observa-se ainda, que a região floemática na face abaxial possui grande quantidade de cristais prismáticos.

\section{Discussão}

A análise morfo-anatômica da lâmina foliar de Pimenta pseudocaryophyllus mostrou características frequientemente observadas em Myrtaceae. Conforme relatado por Solereder (1908) e por Metcalfe \& Chalk (1950), a família possui predominância de cavidades secretoras, complexos estomáticos anomocíticos ou paracíticos, além da presença de numerosos idioblastos portadores de drusas.
Estudos apontam que espécies de Myrtaceae apresentam lâminas foliares dorsiventrais e hipoestomáticas, conforme observado para Eugenia sulcata Spring ex Martius por Machado et al. (1988), para Eugenia cuprea (O. Berg) Mattos e Marlierea suaveolens Cambess. por Callado (1997), para Gomidesia O. Berg por Gomes \& Neves (1997), para Eugenia uniflora L. por Auricchio \& Bacchi (2003), para Eugenia dysenterica DC. por Palhares (2003) e para Psidium widgrenianum por Donato \& Morretes (2005).

A literatura relata ainda que diversas espécies de Myrtaceae apresentam, predominantemente, estômatos paracíticos (Callado 1997; Gomes \& Neves 1997; Auricchio \& Bacchi 2003; Palhares 2003; Donato \& Morretes 2005). Entretanto, em P. pseudocaryophyllus esse tipo de complexo estomático não foi observado. Já os estômatos anomocíticos podem ser observados em Eugenia dysenterica (Palhares 2003), Eugenia cuprea e Marlierea sauveolens (Callado 1997).

Quando se analisa a posição das células estomáticas em relação às demais células epidérmicas, observa-se que poucos são os autores que relatam a sua posição ligeiramente superior, pois, conforme descrito por Reis et al. (2005), a maioria dos representantes de Myrtales possui estômatos nivelados com as demais células epidérmicas. Entretanto, assim como foi observado no presente estudo, Gomes \& Machado (1995) descrevem em Gomidesia nitida e em G. spectabilis a posição ligeiramente elevada das células subsidiárias às epidérmicas, bem como Auricchio \& Bacchi (2003) para Eugenia pyriformis Cambess. P. pseudocaryophyllus ocorre em Floresta Ombrófila Mista, que apresenta árvores que recebem pouca intensidade luminosa. Larcher (2006) observou que plantas que se desenvolvem em locais sombreados, como em Pulmonaria officinalis L. (Boraginaceae), possuem as células estomáticas em posição elevada em relação às demais células epidérmicas.

Segundo Metcalfe \& Chalk (1950), Cutter (1986) e Raven (1996), as células epidérmicas variam de tamanho e forma, podendo apresentar paredes retas, curvas ou sinuosas. Agentes físicos como a intensidade luminosa e a umidade atmosférica interferem no desenvolvimento foliar e constituem um efeito marcante sobre a estrutura das paredes da epiderme. Além desses fatores, a sinuosidade das células da epiderme pode variar conforme a região da folha e de acordo com a presença ou ausência de nervuras (Cutter 1986). De acordo com Solereder (1908), as células com paredes anticlinais curvas ou sinuosas estão adaptadas a ambientes úmidos, enquanto que as células epidérmicas que apresentam paredes retas possuem características que garantem o seu desenvolvimento em ambientes secos. 
Diversos autores descrevem uma cutícula espessa em ambas as faces do limbo foliar de Myrtaceae, dentre eles, Gomes \& Machado (1995) para Gomidesia spectabilis e G. nitida, Solís (2000) para Campomanesia guaviroba (DC.) Kiaersk. e Donato \& Morretes (2005) para Psidium widgrenianum. De acordo com Esau (1960), a espessura da cutícula pode variar e é influenciada pelas condições ambientais. Quando a parede periclinal externa da epiderme possui cutícula espessa, essa pode se depositar entre as paredes anticlinais epidérmicas, formando flanges cuticulares. Nota-se que poucas são as espécies de Myrtaceae que apresentam flanges cuticulares, entretanto Donato \& Morretes (2005; 2007) as descreve em Psidium widgrenianum e Eugenia brasiliensis Lam. Desse modo, essas estruturas podem ser utilizadas para delimitar determinadas espécies, as quais são muito semelhantes morfologicamente. Segundo Carr et al. (1985) apud Gomes \& Machado
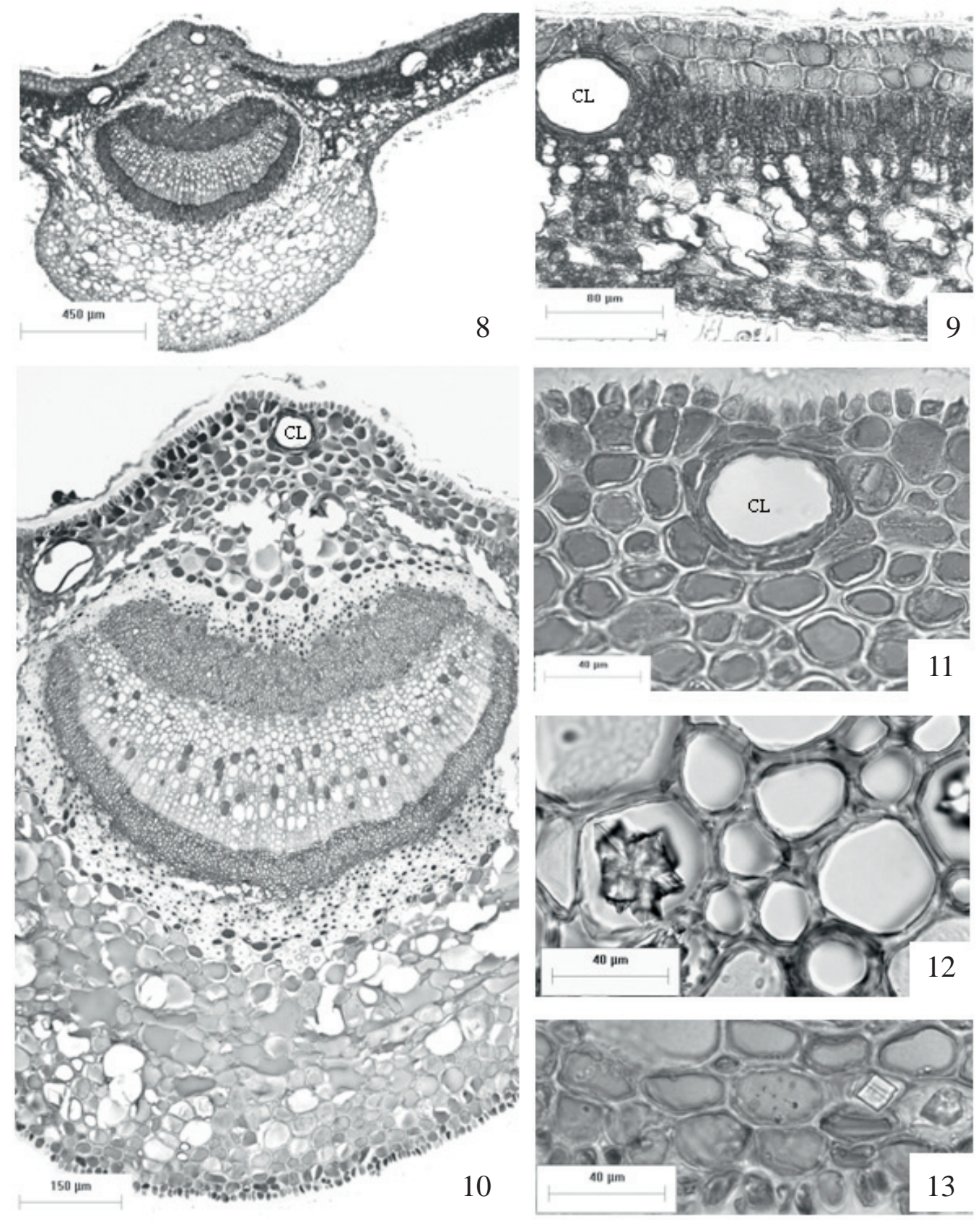

Figuras 8-13. Secção transversal da lâmina foliar de Pimenta pseudocaryophyllus (Gomes) L.R. Landrum. 8. Aspecto geral da nervura central e mesofilo. 9. Mesofilo. 10. Nervura central. 11. Nervura central, em detalhe células epidérmicas, colênquima lacunar e canal lisígeno. 12. Idioblasto portador de drusa. 13. Cristal prismático. ( $\mathrm{CL}=$ canal lisígeno). 
(1995), a camada cuticular recoberta por um depósito de cera forma padrões definidos que também podem ser utilizados como caráter taxonômico em Myrtaceae.

Segundo Reis et al. (2005), células epidérmicas maiores na face adaxial ocorrem em Myrtaceae, Psiloxylaceae, Penaeaceae, Combretaceae, Oliniaceae, Trapaceae, Rynchocalycaceae, Lythraceae, Onagraceae e Vochysiaceae. Donato \& Morretes (2005) também observaram que as células na epiderme adaxial de Psidium widgrenianum possuem maior volume em relação às células epidérmicas na face abaxial.
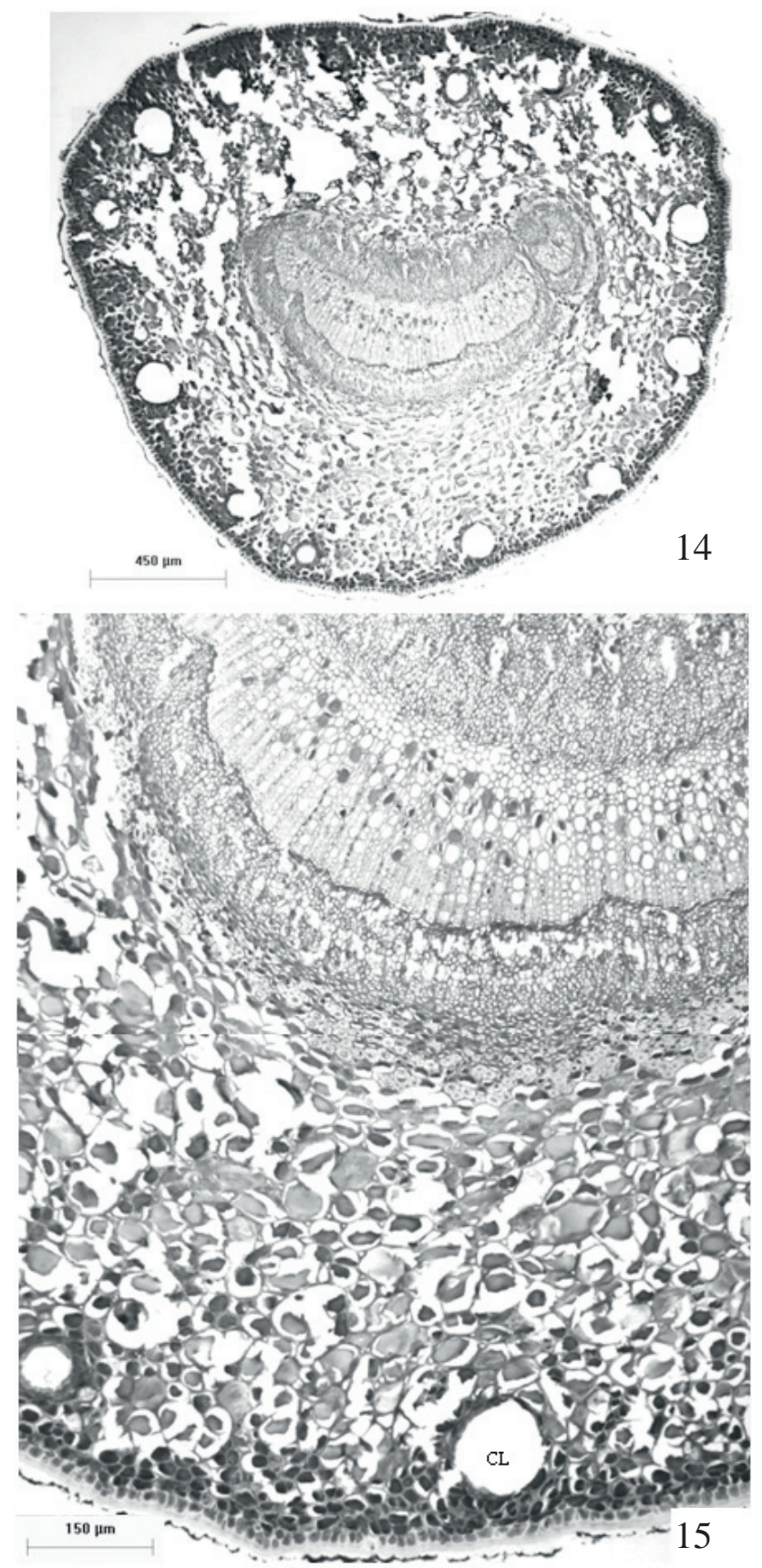

Figuras 14-15. Secção transversal do pecíolo de Pimenta pseudocaryophyllus (Gomes) L.R. Landrum. ( $\mathrm{CL}=$ canal lisígeno).
Metcalfe \& Chalk (1950) relataram que o sistema vascular das Myrtaceae é único, o qual está disposto na forma de arco, que pode ser aberto ou encurvado nas extremidades. Feixes vasculares bicolaterais são reportados para Eugenia sulcata, Gomidesia spectabilis e G. nitida, Eugenia uniflora, Eugenia dysenterica e Psidium widgrenianum (Machado et al. 1988; Gomes \& Neves 1997; Auricchio \& Bacchi 2003; Palhares 2003; Donato \& Morretes 2005). Segundo Reis et al. (2005), a forma do feixe vascular da nervura principal está relacionada com a dimensão dos elementos condutores. Desse modo, feixes planos, arredondados ou em arco determinam nervuras pouco proeminentes e feixes cilíndricos ou com a forma semicircular estão correlacionados com nervuras mais salientes.

Callado (1997) citou que uma faixa contínua de fibras pode envolver o floema, cuja espessura apresenta variação de acordo com a espécie analisada. Fibras esclerenquimáticas estão presentes em Gomidesia nitida e G. spectabilis (Gomes \& Neves 1997), Campomanesia guaviroba (Solís 2000), Eugenia uniflora (Auricchio \& Bacchi 2003) e Psidium widgrenianum (Donato \& Morretes 2005).

Glândulas de origem lisígena, secretoras de óleo, são descritas no mesofilo de Myrtaceae por Machado et al. (1988) para Eugenia sulcata, por Solís (2000) para Campomanesia guaviroba e por Donato \& Morretes (2005) para Psidium widgrenianum.

Idioblastos contendo cristais prismáticos e drusas são recorrentes em várias espécies de Myrtaceae (Machado et al. 1988; Callado 1997; Gomes \& Neves 1997; Auricchio \& Bacchi 2003; Palhares 2003; Cardoso \& Sajo 2004; Donato \& Morretes 2005). Segundo Donato \& Morretes (2005), o tipo, a localização e a frequiência dos cristais facilitam na diagnose da espécie.

De acordo com Pereira et al. (2003), a função exercida pelos tricomas tectores está relacionada com o órgão onde estes se encontram, com sua morfologia, densidade e até mesmo com o ângulo de inclinação. A distribuição intensa de tricomas tectores em folhas e caules constitui uma barreira mecânica contra a alta intensidade luminosa, temperaturas extremas e perda excessiva de água. A presença de tricomas na análise anatômica das folhas coincide com as descrições realizadas por Gomes \& Machado (1995), para as espécies Gomidesia spectabilis e G. nitida, e por Solís (2000), para Campomanesia guaviroba, uma vez que todas essas espécies apresentam tricomas unicelulares no limbo.

A anatomia do pecíolo, conforme Howard (1979) apud Cardoso \& Sajo (2004), pode contribuir na identificação de alguns táxons ou, até mesmo, determinar a família ou o gênero de alguns grupos de plantas. Em estudo realizado com 17 espécies de 
Eugenia, a anatomia do sistema vascular do pecíolo permitiu agrupar as espécies conforme a configuração do arco vascular. Dessa forma, características anatômicas do pecíolo, somadas a outras características da folha, permitem ao taxonomista identificar uma espécie que, macroscopicamente, não possua outras características que facilite a sua identificação (Cardoso \& Sajo 2004).

Várias espécies de Myrtaceae apresentam, no pecíolo, epiderme uniestratificada, cutícula espessa, sistema vascular em arco e bicolateral, além de idioblastos portadores de drusas e cristais no córtex, essas características são descritas para Eugenia cuprea, Marlierea suaveolens, Psidium widgrenianum e E. brasiliensis (Callado 1997; Donato \& Morretes 2005; 2007). Entretanto, algumas características podem ser utilizadas para delimitar espécies ou construir relações filogenéticas, pois são encontradas em poucos representantes, entre estas, podem destacar-se a presença de tricomas unicelulares dibraqueados encontrados em E. cuprea e M. suaveolens (Callado 1997).

Uma das características peculiares ao pecíolo das Myrtaceae é a presença de bainha que envolve o feixe vascular, constituída por células parenquimáticas, esclerificadas ou de estrutura mista. A espessura e o tipo das células que compõem a bainha podem variar, de acordo com a espécie, sendo que alguns autores atribuem valor taxonômico a essa característica (Solereder 1908; Cardoso \& Sajo 2004).

Alguns autores relataram à presença de flanges cuticulares no pecíolo de E. cuprea, M. suaveolens e E. brasiliensis, provavelmente, em decorrência da cutícula espessa e das paredes periclinais espessas dessas espécies (Callado 1997; Donato \& Morretes 2007). Donato \& Morretes (2007) citaram para o bordo foliar de E. brasiliensis a posição levemente fletida em direção a face abaxial, com as células epidérmicas reduzidas em relação às demais porções da lâmina foliar, flanges cuticulares, cavidades secretoras e na porção distal do bordo, colênquima. A posição do bordo de $P$. widgrenianum, entretanto, é descrita como plana em relação à lâmina foliar e observaram-se, também, várias camadas de colênquima na região distal do bordo.

Muitas das estruturas observadas em P. pseudocaryophyllus representam características de folhas xeromorfas. Segundo Esau (1960), folhas que apresentam grande frequiência de estômatos e tricomas, hipoderme, esclerênquima, paredes celulares espessas na epiderme, cutícula grossa e estômatos que ocorrem em cavidades, são de espécies xerófitas, ou seja, constitui plantas que estão aptas a se desenvolver em ambientes secos e com pouca disponibilidade de água. Muitas das estruturas observadas em P. pseudocaryophyllus condizem com as características apontadas por essa autora, entretanto, deve-se atentar que muitas das xeromorfias encontradas atualmente podem constituir adaptações ancestrais e não são, necessariamente, estruturas relacionadas ao habitat atual, no qual a planta se desenvolveu.

\section{Agradecimentos}

As autoras agradecem à Universidade Positivo, Curso de graduação em Ciências Biológicas e Mestrado em Gestão Ambiental.

\section{Referências bibliográficas}

Auricchio, M.T. \& Bacchi, E.M. 2003. Folhas de Eugenia uniflora L. (Pitanga): propriedades farmacobotânicas, químicas e farmacológicas. Revista do Instituto Adolfo Lutz 62: 55-61.

Barroso, G.M. 1984. Sistemática de Angiospermas do Brasil. Viçosa, Imprensa Universitária.

Berlyn, G.P. \& Miksche, J.P. 1976. Botanical microtechnique and cytochemistry. Iowa, Ames.

Callado, C.H. 1997. Anatomia foliar de Eugenia cuprea (Berg) NDZ. e Marlierea suaveolens Gard. (Myrtaceae). Rodriguésia 45/49: 25-37.

Cardoso, C.M.V. \& Sajo, M.G. 2004. Vascularização foliar e identificação de espécies de Eugenia L. (Myrtaceae) da bacia hidrográfica do Rio Tibagi, PR. Revista Brasileira de Botânica 27: 47-54.

Cardoso, C.M.V. \& Sajo, M.G. 2006. Nervação foliar em espécies brasileiras de Myrtaceae Adans. Acta Botanica Brasilica 20: 657-669.

Corrêa, R.G.C. \& Gottlieb, O.R. 1970. O óleo essencial do Pseudocaryophyllus pabstianus. Anais da Academia Brasileira de Ciências 42: 127-128.

Craveiro, A.A.; Fernandez, A.G. \& Andrade, C.H. 1981. Óleos essenciais de plantas do nordeste. Fortaleza, Universidade Federal do Ceará.

Cutter, E.G. 1986. Anatomia vegetal: células e tecidos. São Paulo, Roca.

Donato, A.M. \& Morretes, B.L. 2005. Estudo anatômico das folhas de Psidium widgrenianum Berg. (Myrtaceae), uma potencial espécie medicinal. Revista Brasileira de Farmácia 86: 65-70.

Donato, A.M. \& Morretes, B.L. 2007. Anatomia foliar de Eugenia brasiliensis Lam. (Myrtaceae) proveniente de áreas de restinga e de floresta. Revista Brasileira de Farmacognosia 17: 426-443.

Dorman, H.J.D. \& Deans, S.G. 2000. Antimicrobial agents from plants: antibacterial activity of plant volatile oils. Journal of Applied Microbiology 88: $308-316$.

Esau, K. 1960. Anatomia das plantas com sementes. São Paulo, Edgard Blucher.

Fabris, L.C. \& César, O. 1996. Estudos florísticos em uma mata litorânea no sul do Estado do Espírito Santo. Boletim do Museu de Biologia Mello Leitão 5: 15-46.

Feder, N. \& O'Brien, T.P. 1968. Plant microthecnique: some principles and new methods. American Journal of Botany 55: 123-142.

Fontenelle, J.B.; Costa, C.G. \& Machado, R.D. 1994. Foliar anatomy and micromorphology of eleven species of Eugenia L. (Myrtaceae). Botanical Journal of Linnean Society 115: 111-133.

França, G.S. \& Stehmann, J.R. 2004. Composição florística e estrutura do componente arbóreo de uma Floresta Altimontana no município de Camanducaia, Minas Gerais, Brasil. Revista Brasileira de Botânica 27: 19-30. 
Franklin, G.L. 1946. A rapid method of softering wood for microtome sectioning. Tropical Woods 88: 35.

García, D.; Alvarez, A.; Tornos, P.; Fernandez, A. \& Sáenz, T. 2002. Gas chromatographic-mass spectrometry study of the essential oils of Pimenta racemosa var. terebinthina and P. racemosa var. Grisea. Naturforsch 57c: 449-451.

Gomes, D.M.S. \& Neves, L.J. 1997. Anatomia foliar de Gomidesia spectabilis (DC) Berg. e Gomidesia nitida (Vell.) Legr. (Myrtaceae). Rodriguésia 45/49: 51-70.

Gomes, D.M.S. \& Machado, R.D. 1995. Superfície foliar de Gomidesia spectabilis (DC.) Berg. e Gomidesia nitida (Vell.) Lerg. (Myrtaceae). Acta Botanica Brasilica 9: 271-279.

Gottlieb, O.R.; Koketsu, M.; Moura, L.L.; Moreira, A. \& Magalhães, M.T. 1970. Os óleos essenciais do Pseudocaryophyllus jaccoudii e Calyptranthes sp. Anais da Academia Brasileira de Ciências 42: 143-146.

Johansen, D.A. 1940. Plant microtechnique. New York, Mc Graw Hill Book.

Johnson, C.T. 1980. The leaf anatomy of Leptospermum Forst. Australian Journal of Botany 28: 77-194.

Kraus, J.E. \& Arduim, M. 1997. Manual Básico de Métodos em Morfologia Vegetal. Rio de Janeiro, Edur.

Landrum, L.R. \& Kawasaki, M.L. 1997. The genera of Myrtaceae in Brazil: an illustrated synoptic treatment and identification keys. Brittonia 49: 508-536.

Larcher, W. 2006. Ecofisiologia Vegetal. São Carlos, Rima.

Legrand, C.D. \& Klein, R.M. 1978. Flora ilustrada Catarinense - Mirtáceas. Itajaí, Raulino Reitz.

Lehtonen, M. 1982. Phenols in Whisky. Chromatographia 16: 201-203.

Limberger, R.P.; Apel, M.A.; Sobral, M.; Schapoval, E.S. \& Henriques, A. 1998. Investigação da atividade antimicrobiana do óleo volátil de espécies da família Myrtaceae. Revista Brasileira de Farmácia 79: 49-52.

Lorenzi, H. 2002. Árvores Brasileiras: Manual de Identificação e Cultivo de Plantas Arbóreas Nativas do Brasil. São Paulo, Plantarum.

Machado, D.M.; Costa, C.G. \& Fontenelle, G.B. 1988. Anatomia foliar de Eugenia sulcata Spring ex Mart. (Myrtaceae). Acta Botanica Brasilica 1: 275-285.

Mazzafera, P. 2003. Efeito alelopático do extrato alcoólico do cravoda-índia e eugenol. Revista Brasileira de Botânica 26: 231-238.

Metcalfe, C.R. \& Chalk, L. 1950. Anatomy of the dicotyledons. Oxford, Clarendon Press.

Meyer, S.T.; Silva, A.F.; Junior, P.M. \& Neto, J.A.A.M. 2004. Composição florística da vegetação arbórea de um trecho de floresta de galeria do Parque Estadual do Rola-Moça na Região Metropolitana de Belo Horizonte, MG, Brasil. Acta Botanica Brasilica 18: 701-709.

Miyajima,Y.; Kikuzaki, H.; Hisamoto, M. \& Nakatani, N. 2004. Antioxidative polyphenols from berries of Pimenta dioica. BioFactors 22: 301-303.

Newall, C.A.; Anderson, L.A. \& Phillipson, J.D. 2002. Plantas Medicinais - Guia para profissional da saúde. São Paulo, Premier.
Palkin, S. \& Wells, P.A. 1933. Crystallizable Chavicol and Eugenol from the Oil of Bay - Site 1. Disponível em: <http:// pubs.acs.org/cgi-bin/abstract.cgi/jacsat/1933/55/i04/f-pdf/ f_ja01331a039.pdf?sessid=600613> (Acesso em: 15/02/2007).

Palhares, D. 2003. Caracterização farmacognóstica das folhas de Eugenia dysenterica DC (Myrtaceae Jussieu). Revista Lecta 21: 29-36.

Paula, J.A.M.; Bara, M.T.F.; Rezende, M.H.; Ferreira, H.D \& Paula, J.R. 2005. Estudo farmacognóstico das folhas de Pimenta pseudocaryophyllus (Gomes) L. R. Landrum - Myrtaceae. Revista Eletrônica de Farmácia 2: 153-156.

Pereira, Z.V.; Meira, R.M.S.A. \& Azevedo, A.A. 2003. Morfoanatomia foliar de Palicourea longepedunculata Gardiner (Rubiaceae). Revista Árvore 27: 759-767.

Pereira, I.M.; Oliveira Filho, A.T.; Botelho, S.A.; Carvalho, W.A.C.; Fontes, M.A.L.; Schiavinis, I. \& Silva, A.F. 2006. Composição florística do compartimento arbóreo de cinco remanescentes florestais do Maciço do Itatiaia, Minas Gerais e Rio de Janeiro. Rodriguésia 57: 103-126.

Pinto, L.V.A.; Davide, A.C.; Botelho, S.A.; Oliveira Filho, A.T. \& Machado, E.L.M. 2005. Distribuição das espécies arbóreoarbustivas ao longo do gradiente de umidade do solo de nascentes pontuais da Bacia Hidrográfica do Ribeirão Santa Cruz, Lavras, MG. Revista Cerne 11: 294-305.

Raven, P.H.; Evert, R.F. \& Eichorn, S.E. 1996. Biologia Vegetal. Rio de Janeiro, Guanabara Koogan.

Reis, C.; Bieras, A.C. \& Sajo, M.G. 2005. Anatomia foliar de Melastomataceae do Cerrado do Estado de São Paulo. Revista Brasileira de Botânica 28: 451-466.

Romagnolo, M.B. \& Souza, M.C. 2004. Os gêneros Calycorectes O. Berg, Hexachlamys O. Berg, Myrcianthes O. Berg, Myrciaria O. Berg e Plinia L. (Myrtaceae) na planície alagável do alto rio Paraná, Brasil. Acta Botanica Brasilica 18: 613-627.

Sanjad, N. 2004. Cólera e medicina ambiental no manuscrito 'Choleramorbus' (1832), de Antonio Correa de Lacerda (1777-1852). História, Ciências, Saúde-Manguinhos 11: 587-618.

Sakai, W.S. 1973. Simple method for differential staining of paraffin embedded plant material using toluidine blue. Stain Technology 48: $247-249$.

Solereder, H. 1908. Systematic anatomy of the dicotyledons: a handbook for laboratories of pure and applied botany. Oxford, Claredon.

Solís, S.M. 2000. Estudios morfológicos y anatómicos en hojas con domacios de Campomanesia guaviroba (DC.) Kiaersk. Site 2. Disponível em: <http://www.unne.edu.ar/cyt/2000/ 6_biologicas/b_pdf/b_022.pdf.>. (Acesso em: 15/04/2007).

Souza, V.C. \& Lorenzi, H. 2005. Botânica sistemática. Nova Odessa, Instituto Plantarum.

Starr, F.; Starr, K. \& Loope, L. 2003. Pimenta dióica - Site 3. Disponível em:<http://www.hear.org/starr/hiplants/reports/pdf/ pimenta_dioica.pdf $>$. (Acesso em: 20/02/2007).

Van Wyk A.E.; Robbertse, P.J. \& Kok, P.D.F. 1982. The genus Eugenia L. (Myrtaceae) in southern Africa: the structure and taxonomic value of stomata. Botanical Journal of the Linnean Society 84: $41-56$

Viuda-Martos, M.; Ruiz-Navajas, Y.; Fernández-López, J. \& PérezÁlvarez, J.A. 2007. Antifungal Activities of Thyme, Clove And Oregano Essential Oils. Journal of Food Safety 27: 91-101. 